\title{
The Relationship Between Physical Activity Status and Dietary Habits with the Risk of Cardiovascular Diseases
}

\author{
(D) Asim Alaaeldin Osman1, (1) Zahra Mustafa Abumanga2
}

${ }^{1}$ Gadarif University Faculty of Medicine, Department of Human Physiology and Health Sciences, Gadarif, Sudan

2Omdurman Ahlia University Faculty of Medicine, Department of Physiology, Sudan

\begin{abstract}
Objectives: This study designed to evaluate the relationship between physical activity status and dietary habits with the risk of cardiovascular diseases (CVD).

Materials and Methods: In this cross-sectional study 207 medical students (107 female, 100 male) aged 15-25 years were recruited. Physical activity level and dietary habits assessed by Arab teens lifestyle study questionnaire. Risk of CVD was determined by Framingham, ASSIGN and British National Formulary scoring systems.

Results: In the present study the incidence of CVD was higher in males than females. Female spending more time in sedentary behaviour than male. The incidence of
\end{abstract}

different CVD was higher in male and female that spending more time in sedentary behaviour. Sedentary time, sugary drinks, French fries, potato chips intake were positively correlated with CVD. Eating fresh fruits, energy drinks and dairy products negatively correlated with CVD.

Conclusion: The risk of CVD is higher among male and increase in both sex with physical inactivity and sedentary life style. Sedentary behaviours regarded as independent risk factors for CVD. High sugary diet increases the incidence of CVD and dairy products decrease the incidence of CVD.

Keywords: Cardiovascular diseases, sedentary behaviour, dietary habits

\footnotetext{
Address for Correspondence: Asim Alaaeldin Osman, Gadarif University Faculty of Medicine, Department of Human Physiology and Health Sciences, Gadarif, Sudan

Phone: +24991 4612397 e-mail: asim9517@gmail.com ORCID ID: orcid.org/0000-0003-0483-4988

Received: 18.02.2019 Accepted: 22.05.2019
}

Cite this article as: Osman AA, Abumanga ZM. The Relationship Between Physical Activity Status and Dietary Habits with the Risk of Cardiovascular Diseases. EJCM 2019;7(2):72-78.

DOI: 10.32596/ejcm.galenos.2019.00008 


\section{Introduction}

Recommendation from many recent studies have documented that lifestyle modification in adolescents and young adults are necessary because of the increased tendency of various adverse health outcomes not otherwise typical for their age, including hypertension, dyslipidemia, and metabolic syndromes ${ }^{(1)}$.

It is now well recognised that a physically active lifestyle is associated with decreased cardiovascular diseases (CVD) risk $^{(2)}$. One of the mechanisms for decreased CVD risk with increasing physical activity is through the action of physical activity on established CVD risk factors, such as levels of blood pressure or lipids $^{(3)}$.

Excessive energy intake and sedentary lifestyle in young adults can be associated with the increased prevalence of dyslipidemia, obesity, and $\mathrm{CVD}^{(4)}$. Particularly, sedentary lifestyle (e.g., watching TV) is associated with unhealthy snacking patterns, including low intake of fruits and vegetables and overconsumption of energy and fat ${ }^{(4,5)}$. Because the level of physical activity influences on physical condition, health status, and quality of life, it is important to undertake physical activity of different intensities until the age of 25-30 to maximize the development of motor skills and physical fitness ${ }^{(6,7)}$.

An important time to examine factors associated with CVD risk among adolescents and young adults is during the college years. College students engage in several high risk behaviours associated with CVD development including cigarette smoking, alcohol abuse, physical inactivity, and low fruit and vegetable consumption ${ }^{(8,9)}$. Weight gain is also common among college students ${ }^{(10)}$ with the frequency and magnitude of weight gain the possibility of gaining weight is greater among male than female ${ }^{(11)}$.

Students also perceive that it is acceptable to engage in unhealthy behaviours during their college years, which may be a barrier to incorporating CVD preventive behaviours ${ }^{(8)}$. Because CVD risk behaviours such as physical inactivity, obesity, and smoking increase during the transition from adolescence to emerging adulthood ${ }^{(12)}$. it is critical to have a greater understanding of perceptions related to CVD risk among emerging adults in college.

\section{Materials and Methods}

Observational cross-section study was conducted in Faculty of Medicine, Omdurman Ahlia University, Sudan. Two hundred and seven students (100 male, 107 female) aged 15 to 25 years were participated in this study. Participant with hypertension, diabetes, CVD and those taking lipid lowering drugs was excluded. All students signed a written consent form. Basic anthropometrical measurements including body weight and height were measured; weight was measured by body-weight measuring machine (measurement precision $0.1 \mathrm{~kg}$, SECA device), height was measured using a flexible measuring tape (measurement precision $0.1 \mathrm{~cm}$ )

\section{Assessment of Physical Activity Status and Dietary Habits}

Physical activity and dietary habits were assessed by using Arab Teens Lifestyle Study (ATLS) questionnaire ${ }^{(13)}$. The physical-activity part of the questionnaire intended to collect information on frequency, duration, and intensity of a variety of light-, moderate-, and vigorous intensity physical activities during a typical week and across different activity domains (transport, house hold, fitness, and sports activities). Metabolic equivalent (MET) values were attributed to the physical activities based on the compendium of physical activity and the compendium of physical activity for youth. Physical activity levels were then classified into two categories (active or inactive) based on a cut-off value for total METs-min/week of below or 1,680 MET-min/week. These cut-offs were employed as an score of 1,680 METs-min/week is equivalent to 60 minutes of moderate-intensity daily physical activity (60 minutes 3-7 days 3-4 METs 51,680 METs-min/week), and a score of 2,520 METs-min/week is equivalent to 60 minutes of moderate-to vigorous- intensity daily physical activity (60 minutes 3-7 days 3-6 METs 52,520 METs-min/ 
week). Sedentary behaviours were then assessed by asking how much time in a typical day was spent watching TV, playing video games, and using the computer and internet. To classify total screen time, the "American Academy of Pediatrics" guidelines of a maximum of $2 \mathrm{~h}$ /day was employed.

The dietary habit section of the questionnaire covered healthy and unhealthy dietary behaviours and asked how many times in a typical week the participants consumed breakfast, vegetables (cooked and uncooked), fruit, milk and dairy products, sugar-sweetened drinks including soft beverages, donuts and cakes, candy and chocolate, energy drinks and fast foods. Possible responses ranged from zero intake (never) to a maximum intake of 7 days/week (every day). Participants were then classified into two categories based on the frequency of their intake for each respective food (41 days/week, <4 days/week).

\section{Assessment of the Incidence for CVD}

For assessment of the risk for CVD three CVD scoring systems were used which are Framingham, ASSIGN, and British National Formulary. The variables required for risk calculation by these scoring systems include time in years over which risk is calculated, age of the subjects, sex of the subjects, number of cigarettes smoked per day, smoking status, family history of premature cardiovascular disease, presence of diabetes, presence of left ventricular hypertrophy on ECG, Scottish index of multiple deprivations (usually 20) Systolic blood pressure in $\mathrm{mmHg}$, total cholesterol in $\mathrm{mmol} / \mathrm{L}$ and high density lipoprotein total cholesterol (HDL-C) in $\mathrm{mmol} / \mathrm{L}$.

Venous blood was collected in the morning after an overnight fast of 12 hours. The total cholesterol and HDL-C were measured by using spectrophotometer by kits from Bio-system Company Costa Brara, 30, Barcelona (Spain). Blood pressure was measured by sphygmomanometer.

\section{Statistical Analysis}

Data was analysed by using PASW for Windows ${ }^{\circledR}$ version 24.0 software (formerly SPSS Statistics Inc. Chicago, Illinois). Our data was normally distributed.
Results were presented as mean \pm standard deviations for all variables. Student t-test was used to compared between two groups. Pearson correlation was used to correlate between $\mathrm{CVD}$ and other variables. $\mathrm{P}<0.05$ was considered significant difference.

\section{Results}

Among 207 participants included in the study, 107 of them $(51.7 \%)$ were female, $100(48.3 \%)$ were male. Regarding physical activity 20 (18.7\%) of female and 39 $(39 \%)$ of male regarded as physically active. As shown in Table 1, age, weight, height and the sum of MET which represent the physical activity were statistically significantly higher in male than females $(\mathrm{p} \leq 0.05)$. Results presented in Table 2, showed that the risk of CVD according

Table 1. Anthropometric characteristics and activity status of the study population according to genders

\begin{tabular}{|l|l|l|l|}
\hline Variables & $\begin{array}{l}\text { Male }(\mathbf{n}=100) \\
\text { Mean } \pm \text { SD }\end{array}$ & $\begin{array}{l}\text { Female }(\mathbf{n = 1 0 7}) \\
\text { Mean } \pm \text { SD }\end{array}$ & P value \\
\hline Age (year) & $19.50 \pm 1.58$ & $19.07 \pm 1.10$ & 0.002 \\
\hline Weight $(\mathrm{kg})$ & $67.04 \pm 13.88$ & $60.57 \pm 13.23$ & 0.001 \\
\hline Height $(\mathrm{m})$ & $1.72 \pm 0.64$ & $1.59 \pm .06$ & 0.000 \\
\hline Sum of MET & $1775.08 \pm 1841$ & $1158.3 \pm 1272$ & 0.005 \\
\hline Sedentary time $(\mathrm{h} / \mathrm{d})$ & $1.86 \pm 0.35$ & $1.88 \pm 0.33$ & 0.695 \\
\hline
\end{tabular}

Sum of MET: Sum of metabolic equivalent, $n$ : Number of the patients, $S D$ : Standard deviation

Table 2. Comparison of the different CVD between male and female

\begin{tabular}{|l|l|l|l|} 
Variables & $\begin{array}{l}\text { Male } \\
(\mathbf{n = 1 0 0 )} \\
\text { Mean } \pm \text { SD }\end{array}$ & $\begin{array}{l}\text { Female } \\
(\mathbf{n = 1 0 7 )} \\
\text { Mean } \pm \text { SD }\end{array}$ & P value \\
\hline CVD - Framingham & $0.296 \pm 0.52$ & $1.00 \pm 8.83$ & 0.424 \\
\hline CHD & $0.507 \pm 0.91$ & $0.774 \pm 8.01$ & 0.440 \\
\hline MI & $0.212 \pm 0.54$ & $0.598 \pm 6.19$ & 0.534 \\
\hline Stroke & $0.040 \pm 0.03$ & $0.018 \pm 0.01$ & 0.000 \\
\hline Risk of Death from CHD & $0.002 \pm 0.02$ & $0.591 \pm 6.11$ & 0.337 \\
\hline Risk of Death from CVD & $1.204 \pm 1.30$ & $1.317 \pm 8.67$ & 0.939 \\
\hline CVD - BNF & $0.546 \pm 0.92$ & $0.792 \pm 8.01$ & 0.762 \\
\hline CVD - ASSIGN & $1.727 \pm 1.09$ & $0.599 \pm 0.42$ & 0.000 \\
\hline Systolic BP & $119.47 \pm 9.34$ & $111.93 \pm 7.71$ & 0.000 \\
\hline Diastolic BP & $74.81 \pm 6.99$ & $71.80 \pm 7.39$ & 0.003 \\
\hline
\end{tabular}

CVD: Cardiovascular diseases, CHD: Coronary heart disease, MI: Myocardial infarction, BNF: British National Formulary, BP: Blood pressure, $n$ : Number of the patients, SD: Standard deviation 
to ASSIGN criteria, stroke according to Framingham criteria, systolic blood pressure and diastolic blood pressure were statistically significantly higher in male than females $(\mathrm{p} \leq 0.05)$. As shown in Table 3, only risk of death from coronary heart disease was significantly higher in the inactive male $(\mathrm{p} \leq 0.05)$. Regarding time spending

Table 3. The risk of death from CHD among active and inactive males

\begin{tabular}{l|l|l|l|l|l|}
\hline Variable & Gender & Activity & $\mathbf{n}$ & Mean \pm SD & p value \\
\hline $\begin{array}{l}\text { Risk of Death } \\
\text { from CHD }\end{array}$ & Male & Inactive & 61 & $0.0036 \pm 0.01$ & 0.007 \\
$\begin{array}{l}\text { CHD: Coronary heart disease, } S D: \text { Standard deviation, } n: \text { Number of the } \\
\text { patients }\end{array}$ & Active & 39 & $0.0005 \pm 0.00$ & \\
\hline
\end{tabular}

Table 4. Comparison of different CVD in relation to time spending in sedentary behaviour according to gender

\begin{tabular}{|l|l|l|l|l|l|} 
Variable & Gender & $\begin{array}{l}\text { Sedentary } \\
\text { time }\end{array}$ & $\mathbf{n}$ & Mean \pm SD & $\begin{array}{l}\mathbf{P} \\
\text { value }\end{array}$ \\
\hline MI & Male & $\begin{array}{l}\text { High } \\
\text { Low }\end{array}$ & 86 & $0.239 \pm 0.57$ & 0.04 \\
\hline CVD & Male & $\begin{array}{l}\text { High } \\
\text { Low }\end{array}$ & 86 & $0.046 \pm 0.08$ & \\
\hline -Framingham & & 14 & $0.118 \pm 0.12$ & 0.04 \\
\hline CVD & Male & High & 86 & $1.792 \pm 1.14$ & 0.032 \\
\hline -ASSIGN & & Low & 14 & $1.332 \pm 0.61$ & \\
\hline CVD & Female & High & 94 & $0.567 \pm 0.39$ & 0.39 \\
\hline -ASSIGN & & Low & 13 & $0.831 \pm 0.58$ & 0.58 \\
\hline
\end{tabular}

CVD: Cardiovascular diseases, MI: Myocardial infarction, $n$ : Number of the patients, SD: Standard deviation

Table 5. Correlation of CVD with the sedentary activity in males

\begin{tabular}{|l|l|l|l|}
\hline Variable & Gender & Correlation & $\begin{array}{l}\text { Time spending on } \\
\text { computer per day }\end{array}$ \\
\hline Death from CVD & Male & $\begin{array}{l}\text { Pearson Correlation } \\
\text { Sig. (2-tailed) }\end{array}$ & $\begin{array}{l}0.212^{*} \\
0.034\end{array}$ \\
\hline Systolic BP & Male & $\begin{array}{l}\text { Pearson Correlation } \\
\text { Sig. (2-tailed) }\end{array}$ & \\
\hline Diastolic BP & Male & $\begin{array}{l}\text { Pearson Correlation } \\
\text { Sig. (2-tailed) }\end{array}$ & \\
\hline
\end{tabular}

CVD: Cardiovascular diseases, BP: Blood pressure, Sig: Significance test in sedentary activity results presented in Table 4, showed that the risk of myocardial infarction, CVD according to Framingham criteria is statistically significantly higher in high sedentary male. Risk for development of CVD according to ASSIGN criteria is statistically significant higher in high sedentary male and female $(\mathrm{p} \leq 0.05)$. Regarding correlation of cardiovascular diseases with the time spending in different types of sedentary activity in male results presented in Table 5, showed that the risk of death from CVD statistically significantly positively correlated with time spend on the computer and/or internet per day and watching TV and/or DVD per weekend. Systolic blood pressure and diastolic blood pressure were statistically significantly positively correlated with the watching TV and/or DVD per weekend $(\mathrm{p} \leq 0.05)$. While in female results presented in Table 6, showed that the incidence of CVD according to ASSIGN criteria and stroke according to Framingham is statistically significantly negatively correlated with time spending in watch TV and/or videos per day $(\mathrm{p} \leq 0.05)$. Regarding the correlation of CVD with dietary habits, male results that presented in Table 7, showed that the incidence of CVD according to SSIGN criteria statistically significantly positively correlated with eating fresh fruit. Systolic blood pressure

Table 6. Correlation of CVD with the sedentary activity in females

\begin{tabular}{|c|c|c|c|}
\hline Variable & Gender & Correlation & $\begin{array}{l}\text { Watching TV or videos } \\
\text { per day }\end{array}$ \\
\hline Stroke & Female & $\begin{array}{l}\text { Pearson Correlation } \\
\text { Sig. (2-tailed) }\end{array}$ & $\begin{array}{l}-0.237^{\star} \\
0.014\end{array}$ \\
\hline CVD-ASSIGN & Female & $\begin{array}{l}\text { Pearson Correlation } \\
\text { Sig. (2-tailed) }\end{array}$ & $\begin{array}{l}-0.209^{*} \\
0.032\end{array}$ \\
\hline
\end{tabular}


significantly negatively correlated with drinking energy drinks. Diastolic blood pressure statistically significantly positively correlated with sugar drink and negatively correlated with eating fresh fruit. While the female results that presented in Table 8, showed that systolic blood pressure statistically significantly negatively correlate with eating diary product. Diastolic blood pressure statistically significantly negatively correlated with eating French fries or potato chips, sweet and chocolate $(\mathrm{p} \leq 0.05)$.

\section{Discussion}

The present study revealed that most our college students were physically inactive and spending their time in sedentary activities, These findings concur with a number of previous studies ${ }^{(8,9)}$. Moreover, our results indicated that development of CVD diseases was higher in male than female, this in accordance with the investigators that suggest the lifetime risk for developing CVD is higher among men than women ${ }^{(14)}$ across most age groups ${ }^{(15)}$. Emerging adult males, those $18-25$ years of age, ${ }^{(16)}$ may be particularly at risk for engaging in CVD risk behaviours due to greater independence, less parental monitoring, and financial instability. Cardiovascular risk factors established during adolescence and emerging

Table 7. Correlation of CVD with the dietary habits in males

\begin{tabular}{|l|l|l|}
\hline Variable & Gender & Correlation \\
\hline CVD-ASSIGN & Male & $\begin{array}{l}\text { Pearson Correlation } \\
\text { Sig. (2-tailed) }\end{array}$ \\
\hline Systolic BP & Male & $\begin{array}{l}\text { Pearson Correlation } \\
\text { Sig. (2-tailed) }\end{array}$ \\
\hline Diastolic BP & Male & $\begin{array}{l}\text { Pearson Correlation } \\
\text { Sig. (2-tailed) }\end{array}$ \\
\hline CVD: Cardiovascular diseases, BP: Blood pressure, Sig: Significance test
\end{tabular}

Table 8. Correlation of CVD with the dietary habits in females

\begin{tabular}{|l|l|l|}
\hline Variable & Gender & Correlation \\
\hline Systolic BP & Female & $\begin{array}{l}\text { Pearson Correlation } \\
\text { Sig. (2-tailed) }\end{array}$ \\
\hline Diastolic BP & Female & $\begin{array}{l}\text { Pearson Correlation } \\
\text { Sig. (2-tailed) }\end{array}$ \\
\hline CVD: Cardiovascular diseases, BP: Blood pressure, Sig: Significance test
\end{tabular}

adulthood have been shown to extend into later adulthood, ${ }^{(17)}$ increasing the risk for CVD. In the current study we observed that the risk of CVD was higher in physically inactive male than physically active ones. Furthermore, the risk of CVD was higher in the high sedentary male and female. These finding agree with the recommendation for ideal cardiovascular health that adopted by the American Heart Association which included lifestyle-related recommendations for physical activity and dietary behaviours, not smoking, and a body mass index less than $25 \mathrm{~kg} / \mathrm{m}^{2(18)}$.

In the current study it is clear that sedentary behaviour is independent risk factor for different type of CVD and its risk factors in male and females, this finding agree with a number of previous studies that conclude prolonged sedentarism is regarded as independent risk factor for CVD independent of physical activity and other potentially confounding factors ${ }^{(19,20)}$. Moreover regarding physical inactivity pattern that potentially affect the CVD, our finding showed that the time spending on the computer and/or internet per day and watching TV was significantly associated with the CVD and its associated risk factors in male and females, these findings are in accordance with a research that reported TV watching appear to be separate 
entities and is independently associated with cardiometabolic risk ${ }^{(21,22)}$.

Regarding association between dietary habits and CVD we observed that in males, the sugary drinks increases the diastolic blood pressure, eating French fries and/or potato chips decreases diastolic blood pressure. While in females the dairy products significantly decrease systolic blood pressure, eating French fries and/or potato chips, sweets and/or chocolates decreases the diastolic blood pressure.

Furthermore, present study found that high consumption of fruit, increases the risk for development of CVD according to ASSIGN this might be due to intake of high sugary fruit juices with fast food.

\section{Study Limitations}

This study is limited in the term of calculation of incidence of cardiovascular diseases because we used cross-sectional study that is suitable to our study population.

\section{Conclusion}

The risk of cardiovascular diseases is higher among male and increases in both sex with physical inactivity and sedentary life style. Sedentary behaviours regarded as independent risk factors for cardiovascular diseases. High sugary diet increases the incidence of cardiovascular diseases and dairy products decrease the incidence of cardiovascular diseases.

\section{Ethics}

Ethics Committee Approval: This study approved by ethical committe of the faculty of medicine International Africa University (number 27-2017)

Informed Consent: Informed consent was obtained from the patients.

Peer-review: Externally and internally peer-reviewed.

\section{Authorship Contributions}

Concept: A.A.O., Z.M.A, Design: A.A.O., Z.M.A., Data Collection or Processing: A.A.O., Z.M.A.,
Analysis or Interpretation: A.A.O., Z.M.A., Literature Search: A.A.O., Z.M.A., Writing: A.A.O., Z.M.A.

Conflict of Interest: No conflict of interest was declared by the authors.

Financial Disclosure: The authors declared that this study received no financial support.

\section{References}

1. Anthony D, George P, Eaton CB. Cardiac risk factors: new cholesterol and blood pressure management guidelines. FP Essent 2014;421:28-43.

2. US Department of Health and Human Services (DHSS). Physical Activity and Health: A Report of the Surgeon General. Atlanta, GA: US DHSS, Centers for Disease Control and Prevention, National Center for Chronic Disease Prevention and Health Promotion; 1996.

3. Wannamethee SG, Shaper AG. Physical activity in the prevention of cardiovascular disease: an epidemiological perspective. Sports Med 2001;31:101-14.

4. Chapman CD, Nilsson VC, Thune HÅ, et al. Watching TV and food intake: the role of content. PLoS One 2014;9:e100602.

5. Ganesh JS, Rao YY, Ravikumar R, et al. Beneficial effects of black yeast derived 1-3, 1-6 Beta Glucan-Nichi Glucan in a dyslipidemic individual of Indian origin--a case report. J Diet Suppl 2014;11:1-6.

6. Blair SN, Cheng Y, Holder JS. Is physical activity or physical fitness more important in defining health benefits? Med Sci Sports Exerc 2001;33(Suppl 6):379-99.

7. Chakravarthy MV, Joyner MJ, Booth FW. An obligation for primary care physicians to prescribe physical activity to sedentary patients to reduce the risk of chronic health conditions. Mayo Clin Proc 2002;77:165-73.

8. Arnett JJ. Emerging adulthood. A theory of development from the late teens through the twenties. Am Psychol 2000;55:469-80.

9. Nelson MC, Story M, Larson NI, Neumark-Sztainer D, Lytle LA. Emerging adulthood and college-aged youth: an overlooked age for weight-related behavior change. Obesity (Silver Spring) 2008;16:2205-11.

10. Racette SB, Deusinger SS, Strube MJ, Highstein GR, Deusinger RH. Changes in weight and health behaviors from freshman through senior year of college. J Nutr Educ Behav 2008;40:39-42.

11. Driskell JA, Meckna BR, Scales NE. Differences exist in the eating habits of university men and women at fast-food restaurants. Nutr Res 2006;26:52430

12. Harper S, Lynch J. Trends in socioeconomic inequalities in adult health behaviors among U.S. states, 1990-2004. Public Health Rep 2007;122:17789

13. Al-Hazzaa HM, Musaiger AO; ATLS Research Group. Arab Teens Lifestyle Study (ATLS): objectives, design, methodology and implications. Diabetes Metab Syndr Obes 2011;4:417-26.

14. Lloyd-Jones DM, Leip EP, Larson MG, et al. Prediction of lifetime risk for cardiovascular disease by risk factor burden at 50 years of age. Circulation 2006;113:791-8 
15. Wilkins JT, Ning H, Berry J, et al. Lifetime risk and years lived free of total cardiovascular disease. JAMA 2012;308:1795-801.

16. Arnett JJ. Emerging adulthood. Emerging adulthood. A theory of development from the late teens through the twenties. Am Psychol 2000;55:469-80.

17. Gordon-Larsen P, The NS, Adair LS. Longitudinal trends in obesity in the United States from adolescence to the third decade of life. Obesity (Silver Spring) 2010;18:1801-4.

18. Lloyd-Jones DM, Hong Y, Labarthe D, et al. Defining and setting national goals for cardiovascular health promotion and disease reduction: the American Heart Association's strategic Impact Goal through 2020 and beyond. Circulation 2010;121:586-613.
19. Owen N, Sparling PB, Healy GN, Dunstan DW, Matthews CE. Sedentary behavior: emerging evidence for a new health risk. Sedentary behavior: emerging evidence for a new health risk. Mayo Clin Proc 2010;85:113841

20. George ES, Rosenkranz RR, Kolt GS. Chronic disease and sitting time in middle-aged Australian males: findings from the 45 and Up Study. Int J Behav Nutr Phys Act 2013;10:20.

21. Physical Activity Guidelines Advisory Committee. PhysicalActivity Guidelines Advisory Committee Report, US Department of Health and Human Services, Washington, DC, USA; 2008.

22. Martinez-Gomez D, Rey-López JP, Chillón P, et al. Excessive TV viewing and cardiovascular disease risk factors in adolescents. The AVENA crosssectional study. BMC Public Health 2010;10:274. 